\title{
Human Development and Regional Disparities in Iran: A Policy Model
}

\author{
F. Noorbakhsh \\ Centre for Development Studies \\ Department of Economics \\ University of Glasgow \\ Glasgow - UK \\ Email:f.noorbakhsh@socsci.gla.ac.uk
}

\begin{abstract}
This paper argues that the future of the Human Development Index published by the United Nations depends on how successfully this index becomes operational and this is more likely to be possible at the country level for a variety of reasons. With this in mind the paper proposes a method and a model for the systematic reduction of regional disparities in the Islamic Republic of Iran, a problem which is of serious concern to policy makers in Iran at present. A number of indicators of education, health and economic welfare, from the recent Human Development Report of Iran 1999, are employed to compare 26 provinces (regions) of Iran. This paper proposes (i) a method for combining the data into a composite index of development and thereby ranking provinces with respect to their overall development; (ii) it proposes a method for capturing the extent of regional disparities with respect to the selected indicators and (iii) it suggests a way of including the results into a policy model which aims at the systematic reduction of regional disparities in Iran. For this purpose it computes a set of targets for various provinces and suggests a way of adjusting these targets.
\end{abstract}




\section{Human Development and Regional Disparities in Iran: A Policy Model}

\section{Introduction}

Measuring development has been a matter of debate for nearly half a century. The conventional way of assessing development by economic indicators only has been challenged many times during this period. $\square$

As early as 1954 a report by the United Nations on social policy and planning regarded economic growth as a requirement for better living standards rather than the ultimate policy aim (UN 1954). In 1969 experts on social policy and planning warned that " The fact that [economic] development either leaves behind, or in some ways even creates, large areas of poverty, stagnation, marginality, and actual exclusion from economic and social progress is too obvious and too urgent to be overlooked." (UN 1969, p5). Nearly a decade later a group of prominent scholars suspected that "... the economic growth by itself may not solve or even alleviate the problem [ of poverty ] in any reasonable time period." (Ahluwalia 1976, p1). Some suggested that development should be seen as “... creating the conditions for realisation of human potentiality" (Seers 1972). Others argued for a change in the objectives of development programmes and proposed the satisfaction of basic needs as a replacement for purely macroeconomic objectives (Hicks and Streeten 1979, Streeten et al. 1981) thus attempting to move the emphasis towards human objectives. The most important deficiency of the traditional development economics was regarded to be its "concentration on national product, aggregate income and total supply of particular goods rather than on entitlements of people and the capabilities these entitlements generate." (Sen 1984, p 496).

Such concerns resulted in searching for alternative measures of human welfare (development). The most recent attempt in constructing a measure of human development is the annual publication of the Human Development Report (HDR) and Human Development Index (HDI) by the UNDP which has been used for ranking countries since 1990. This index has been favoured on the grounds that it shows the inadequacy of other indices such as GNP (Streeten 1994 and 1995). ${ }^{\text {G }}$ It has been preferred to per capita income as the latter neglects the distributional aspects (Desai 1993) and it has been suggested that it "captures many aspects of human development" (Haq 1995, p54). 
Since its publication the HDI has attracted the public and policy makers' attention in developing countries as well as in international organisations. ${ }^{5}$ Once again the HDI has brought the importance of social issues to the forefront. However, in a recent United Nations conference a number of influential advocates of HDI rightly pointed out that we now should be thinking about the future of HDI.

The history of the use of socioeconomic indicators and the composite measures of development based on these indicators has shown that if such measures are not geared to policy making their effects are limited and at best they can have a limited consequence for the way we consider them. Ward (1999) notes that "When instituted, the PQLI (physical quality of life index) had some immediate policy impact on how American Government through USAID allocated its aid support to developing countries." (p 3-4). However, this did not last long. The fact that the existing President of the World Bank, almost half a century after the UN report (in 1954), has to reiterate what was practically mentioned in the above report is an alarming indication that we have made little progress in succeeding to include social aspects adequately in the policy making process.

\section{Operationalising HDI}

At present the most HDR and HDI can do is to convince the decision makers that attaining a high level of health, education and economic growth is desirable. This has already been accepted by most policy makers in developing countries. Given the multiplicity of objectives the question is how do we go about including these in the policy formulation process?

Commenting on the future research on the HDI Streeten (2000) advocates that one area of concentration for research should be the practical use of the index to policy making in developing countries. He points out that a way forward with HDI is the operationalisation of its concept and asks "How can the HDI be used for appraising (ex ante) and evaluating (ex post) projects and programmes? Can it be incorporated in project analysis? Can it be used for allocating aid by donors?" (p 29). An index is not only to measure a composite phenomenon but also it should be operational if it is to remain meaningful. Indeed the UNDP has now entered the next phase of the HDI. It should concentrate on making the approach more policy relevant and this may mean some changes to the index. The future of the HDI as seen by the UNDP depends on how successfully it becomes operational. 
The HDI in its present form has to be general enough to be applicable to all countries. While this is understandable, nevertheless, it limits the operational capability of the index for an individual country. At the country level it would be unreasonable to preserve the generality of the HDI at the cost of neglecting the specific characteristics and policy concerns of the country. In this respect the UNDP initiative of encouraging the publication of country HDI reports is an initial step in bringing the general concept a step closer to being included in the policy making process at the country level.

One possible way of making the underlying concept of HDI within a specific country more policy oriented is through the regional policy framework. Regional disparities within most developing countries have been increasing at an alarming pace. The traditional economic planning with economic growth as its ultimate target tends to overlook the problem of distribution to a considerable extent if not totally. We still know very little about the dynamics of growth and distribution (Ward 1999). One of the main reasons for such a neglect, amongst others, is the difficulty of implementing distributional policies. However, policies aiming at the reduction of disparities amongst regions are steps in the right direction.

Regions within a country may be behind other regions in terms of income arising from economic activities. When this is combined with social income poverty due to less access to goods and services provided by the public sector it results in the region being seriously left behind the rest of the country. ${ }^{8}$ Inevitably there is the perpetual effect of the latter on the former type of poverty.

Iran is no exception to this process. Regional disparities in Iran have been growing at an alarming rate leading to serious problems including migration with its associated problems from backward provinces to the more affluent ones. The recent Human Development Report for Iran reflects such disparities and reiterates that one of the major human development policies in the country's Third Plan is to "pay attention to the spatial planning as a long-term framework for social justice and regional balance" (Plan and Budget Organisation and United Nations and United Nation (1999), p 141). With the intention of making the HDI more policy oriented this article proposes a model for the systematic reduction of regional disparities in Iran. 


\section{The data}

The data cover sixteen socioeconmic indicators for 26 different provinces of Iran. The selected indicators measure various socieconomic aspects of life in provinces of Iran. A number of points should be made regarding the data. The selected indicators should have the property of being operational. By that we mean that it should be possible to have an effect on aspects measured by these indicators through the implementation of projects and policies. While the need for further discussion of the theoretical issues regarding the selection of indicators is acknowledged we do not address such issues in this article. ${ }^{\text {日 }}$ However, we have attempted to select a set of indicators which are within the spirit of the components of the HDI.

Sixteen indicators for which regional data is available are selected. They include five indicators of longevity, health and poverty, six indicators of education (and gender) and five economic indicators. ${ }^{0}$ The list of the selected indicators is presented in Appendix A. Table B1 in Appendix B presents the data for these indicators.

\section{Methodology}

We start with the matrix of data, $\mathrm{X}$, containing data on $\mathrm{m}$ socio-economic indicators for $\mathrm{n}$ provinces. To remove the scale effect and to have the indicators spread around the same mean with the same variance, we first standardise the data. The standardised indicators would then constitute $\mathrm{m}$ vectors in a multi-dimensional vector space. Conceptually this makes sense as any composite socio-economic index for human development should be defined within the context of all provinces. As the length of a standardised indicator is equal to the square root of the number of provinces which remains the same for all indicators, the length of the standardised indicator vectors are equal.

With this property, in turn these vectors of equal length can constitute the axes of a space within which each province is presented by a vector. In effect in the standardised data matrix, where rows and columns are the provinces and indicators respectively, the vector space consists of the row vectors and the matrix columns are a co-ordinate system for this space. In other words each province can be mapped as an m-dimensional vector in the space of the selected indicators. The distance between any two such vectors may then be measured by the length of the so-called distance vector. 
We can be concerned with the distance vector between province $\mathrm{i}$ and the province with the maximum standardised score for an individual indicator (the province with the ideal score). The length of the distance vector, $d_{i}$ containing $m$ components, from the ideal province(s) for province $\mathrm{i}$ is then measured by:

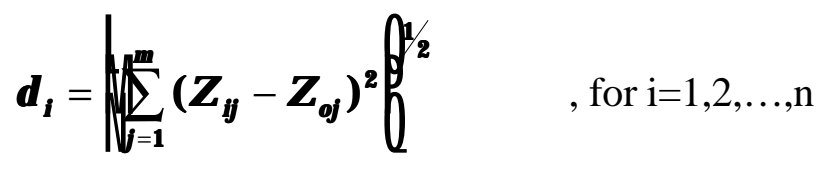

where $Z_{o j}$ is the highest standardised score for indicator $j$. The lower the $d_{i}$ the better the position of province i relative to the ideal province. We can rank different provinces according to the value of $d_{i}$. It should be noted that as in the case of the HDI the components of this regional composite index are treated as having equal weights.

To continue with the tradition of HDI we may wish to express these measures in the form of an index whose values remain between 1 and 0 . As we have now effectively a single index, though composite, the re-scaling of the results, to between 0 and 1 , will have no bearing on the ranking order. In fact we have a number of options. We can divide the results by the maximum value in the set or we may use an approach similar to the one adopted by the UNDP for re-scaling the results. Alternatively we may follow the approach suggested by Noorbakhsh (1998) and define our regional modified human development index (RHDI) as follows.

$$
\boldsymbol{R} \boldsymbol{H} \boldsymbol{D} \boldsymbol{I}_{\boldsymbol{i}}=\mathbf{1}-\frac{\boldsymbol{d}_{\boldsymbol{i}}}{\boldsymbol{d}+\boldsymbol{k s}_{\boldsymbol{d}}} \quad, \text { for } \mathrm{I}=1,2, \ldots, \mathrm{n}
$$

where $\bar{d}$ and $\mathrm{s}_{\mathrm{d}}$ are the mean and standard deviations of $d_{i}$. The parameter $\mathrm{k}$ is determined such that the value of the second expression on the right hand side of equation (2) for all provinces would remain between 1 and 0 (as we desire that the value of the RHDI to be between 1 and 0 ). Interestingly the selected value for $\mathrm{k}$ which would satisfy the above requirement would also point at the extent of deviation of the distribution from that of the normal distribution. If the distribution is normal setting $\mathrm{k}=2$ should result in $95 \%$ of our provinces ending up with an RHDI value falling between 1 and 0 . For this value of $k$ only one province (Sistan and Baloochestan) out of 26 fell outside the desired range. In practice for $\mathrm{k}=2.6$ all countries fell within the required range. The results are presented in Table 1. The nearer the RHDI to 1 the more developed is the province, in terms of the selected indicators, and vice versa. 
Table 1. Ranking of provinces by the composite regional human development index (RHDI)

\begin{tabular}{lccc}
\hline \hline \multicolumn{1}{c}{ Province } & Rank & RHDI & Difference \\
23. Tehran & 1 & 0.762 & \\
20. Qom & 2 & 0.641 & 0.121 \\
10. Isfahan & 3 & 0.590 & 0.051 \\
25. Yazd & 4 & 0.516 & 0.074 \\
21. Semnan & 5 & 0.501 & 0.015 \\
18. Markasi & 6 & 0.495 & 0.006 \\
5. Fars & 7 & 0.483 & 0.012 \\
6. Gilan & 8 & 0.457 & 0.026 \\
12. Kermanshah & 9 & 0.434 & 0.023 \\
11. Kerman & 10 & 0.434 & 0.000 \\
19. Mazandaran & 11 & 0.429 & 0.005 \\
13. Khoozestan & 12 & 0.427 & 0.002 \\
4. East Azarbayjan & 13 & 0.424 & 0.003 \\
2. Booshehr & 14 & 0.399 & 0.025 \\
17. Lorestan & 15 & 0.376 & 0.023 \\
9. Ilam & 16 & 0.368 & 0.008 \\
14. Khorasan & 17 & 0.356 & 0.012 \\
3. Chahar Mahal B. & 18 & 0.355 & 0.001 \\
7. Hamedan & 19 & 0.348 & 0.007 \\
8. Hormozgan & 20 & 0.309 & 0.039 \\
1. Ardebil & 21 & 0.307 & 0.002 \\
26. Zanjan & 22 & 0.263 & 0.044 \\
24. West Azarbayjan & 23 & 0.221 & 0.042 \\
15. Kohkilooyeh \& B. A. & 24 & 0.211 & 0.010 \\
16. Kordestan & 25 & 0.197 & 0.014 \\
22. Sistan \& B. & 26 & 0.000 & 0.197 \\
\hline
\end{tabular}

The last column of Table 1 shows the difference in RHDI between consecutive provinces. The figure for the distance between the top province, Tehran, and the next province, Qom, is strikingly high indicating that Tehran is by far the most advanced province. The difference between Qom, Isfahan and Yazd are relatively high as compared to those for the rest of the provinces with the exception of Sistan Baluchestan. Indeed the figure for the latter province indicates that it is by far the most backward province in the whole country. It is interesting to note that the difference between Sistan and Baluchestan and it s next best province ( Kordestan which is also a backward province) is much larger than the difference between Tehran and Qom. The differences between the RHDI scores of the remaining provinces, as compared to these extreme cases, are relatively smaller. 


\section{Homogeneous groups}

Meanwhile for all provinces we can compute the elements of a distance matrix D which represents the composite distances as measured by $m$ indicators.

$$
\mathrm{d}_{\mathrm{pq}}=\left[\sum_{j=1}^{m}\left(Z_{p j}-Z_{q j}\right)^{2}\right]^{1 / 2} \quad, \text { for } \mathrm{p}=1,2, \ldots, \mathrm{n} ; \text { and } \quad \mathrm{q}=1,2, \ldots, \mathrm{n}
$$

Every element of matrix D is a mathematical expression of several distances (as many as the number of indicators) between two provinces of $\mathrm{p}$ and $\mathrm{q}$. This matrix is presented in Table B2 in Appendix B. Across every row of this matrix the minimum non-zero value shows the shortest distance between two closest provinces represented by the respective row and column. Every province can be connected to its closest neighbour by means of an arrow. This will result in a set of disconnected sub-sets of first order graphs which represent the first order homogeneous provinces in close neighbourhood. Second order connections may be determined in the same way. Links with values above a certain critical value may be regarded as too far to indicate close neighbourhood. Similarly distances below a lower bound indicate almost identical provinces. These critical upper and lower values are represented by $d_{(+)}$and $d_{(-)}$and are found as follows:

$$
\begin{aligned}
& \mathrm{d}_{(+)}=\overline{\mathrm{d}}+2 \mathrm{~s}_{\mathrm{d}} \\
& \mathrm{d}_{(-)}=\overline{\mathrm{d}}-2 \mathrm{~s}_{\mathrm{d}}
\end{aligned}
$$

where $\bar{d}$ and $s_{d}$ are the mean and standard deviation of all minimum distances belonging to $n$ provinces. $\frac{12}{12}$ The upper bound $\mathrm{d}_{(+)}$may be regarded as the critical minimum distance. If the composite distance between two provinces falls below this value these two provinces may be regarded to be in the neighbourhood of each other that is they are members of a homogenous group. All links with a length greater than the value of this upper bound may be removed since they are too long to be part of a single graph. Theoretically any composite distance value below $\mathrm{d}_{(-)}$indicates that the two provinces are practically similar. Table B2 in Appendix B shows the interregional distances and the neighbour of each province along with the critical distances of $\mathrm{d}_{(+)}$and $\mathrm{d}_{(-)}$. 
Groups of close neighbouring provinces found by drawing the first order graphs are presented in Table 2. The second column of this table shows the average of the distances between the immediate neighbours in the group. This figure may be regarded as an index of resemblance within the group, the smaller this figure the higher the resemblance between all members of the group. It may also be compared with the bench mark values provided by $d_{(+)}(=4.462)$ and $d_{(-)}$ $(=1.288)$.

Table 2. Homogenous groups of provinces

\begin{tabular}{|c|c|c|c|}
\hline $\begin{array}{l}\text { Neighbouring groups of the first } \\
\text { degree }\end{array}$ & $\begin{array}{l}\text { Degree of } \\
\text { heterogeneity } \\
\text { within the } \\
\text { group }\end{array}$ & $\begin{array}{c}\text { Closest } \\
\text { neighbour to } \\
\text { the group }\end{array}$ & $\begin{array}{l}\text { Distance of the } \\
\text { closest } \\
\text { province to the } \\
\text { group }\end{array}$ \\
\hline Qom, Tehran. & 4.031 & Fars & $4.854 *$ \\
\hline Isfahan, Semnan, Yazd. & 2.395 & Mazandaran & 3.348 \\
\hline $\begin{array}{l}\text { Booshehr, Fars, Gilan, Hormozgan, } \\
\text { Khoozestan, Mazandaran. }\end{array}$ & 2.690 & Kerman & 2.715 \\
\hline $\begin{array}{l}\text { Char Mahal B., East Azarbayjan, } \\
\text { Hamedan, Khorasan, Markazi. }\end{array}$ & 2.714 & Ardebil & 2.533 \\
\hline Ilam, Kerman, Kermanshah, Lorestan & 2.559 & Mazandaran & 2.715 \\
\hline $\begin{array}{l}\text { Ardebil, Kohkiloyeh, Kordestan, West } \\
\text { Azarbayjan, Zanjan. }\end{array}$ & 2.801 & $\begin{array}{c}\text { East } \\
\text { Azarbayjan }\end{array}$ & 2.533 \\
\hline Sistan and Baloochestan. & $*$ & $\begin{array}{c}\text { West } \\
\text { Azarbayjan }\end{array}$ & $5.549 *$ \\
\hline
\end{tabular}

Distance larger than the critical minimum distance of $\mathrm{d}_{(+)}$.

Columns 3 and 4 of Table 2 show the closest province to the group and its distance (second order links) from a member of the group. These provinces are found by searching for the minimum value amongst the next (second) minimum distances for all members of the group.

The degree of heterogeneity within the first group is rather large, once again indicating that Tehran is by far the most developed province. It is interesting to note that the distance of the closest province to this group is above the minimum critical distance making the closest province to the group heterogeneous to the group by our criteria. The last group in Table 2 includes only one province, Sistan and Baluchestan indicating that this most backward 
province is not homogeneous to any other province in the country. The distance of the closest province to this province is far above our minimum critical distance. At the same time this closest province would be also the closest neighbour to the group as there is only one member in this group.

\section{Determining regional targets}

One of the important steps in planning is the choice of targets. Sometimes these targets are obtained by considering the potential capacity of a country, defined by its past performance and sometimes by considering the status of the neighbouring countries or regions. Such an approach for regional planning within a country is more justified since it may be utilised for the purpose of reducing regional disparities within the context of a national plan/programme. In this case a simple and logical approach is to answer the following questions: (a) which regions are at a higher level of development? And (b) how far are they, in terms of development, from each other (what are the extent of disparities)?

The above approach can help us to answer these questions. The first question is answered by obtaining the RHDI and the next question may be answered by studying the matrix of distances, $\mathrm{D}$, in Table B2. This matrix provides the required information for determining the homogeneous groups of provinces. The average of actual values of indicators for those provinces which are homogenous to province $\mathrm{p}$ and also have a higher RHDI than province $\mathrm{p}$ may be taken as the approximate potential targets for province $\mathrm{p}$.

At this stage, the procedure may be summarised as follows:

1. Compute the RHDI and rank the provinces accordingly (Table 1)

2. Compute the matrix of distances $\mathrm{D}$ and compute $\mathrm{d}_{(+)}$and $\mathrm{d}_{(-)}$(Table B2).

3. To find the targets for province $\mathrm{p}$ look at the $\mathrm{p}^{\text {th }}$ row of matrix $\mathrm{D}$ and determine all provinces whose distances from province $\mathrm{p}$ are between $\mathrm{d}_{(+)}$and $\mathrm{d}_{(-)}$.

4. Exclude from this group those provinces which are at a lower level of development than province $\mathrm{p}$ according to the RHDI.

5. The averages of actual values for indicators belonging to the remaining members of the group and province $\mathrm{p}$ itself would constitute a set of acceptable and attainable targets for province $\mathrm{p}$. 
The target for all provinces can be computed using the above procedure. For example the targets for province 19 (Mazandaran) is computed as follows.

From Table B2 we can see that all provinces are homogenous to this province with the exceptions of provinces 15,16,20,22, 23 and 24 as these have a distance higher than the minimum critical distance with province 19. From the remaining provinces only provinces 5, $6,10,11,12,18,21$ and 25 have a higher level of RHDI than this province (see Table 1). These provinces, and province 19, provide a basis for computing the targets for this province from Table B1. The average targets for province 19 computed from these remaining provinces (and province 19) are presented in Table 3 next to actual values for the selected indicators.

Table 3. Actual values and computed targets

\section{for province 19 (Mazandaran) for all indicators}

\begin{tabular}{ccc}
\hline Indicator & Actual value & Target value \\
\hline LE & 67.4 & 67.7 \\
AL & 72 & 74.1 \\
RCPC & 1557 & 1732 \\
SFWA & 93 & 94.7 \\
SANA & 64.6 & 71.6 \\
RCP20 & 371 & 419.4 \\
FPENR & 97.3 & 97.9 \\
FSENR & 67 & 64.8 \\
INFS & 961.1 & 961.8 \\
MATS & 972 & 972.2 \\
PENR & 116.6 & 118.4 \\
SENR & 84.2 & 80.8 \\
R\&DST & 35.1 & 58.0 \\
LF & 26.8 & 27.4 \\
LFIND & 22.3 & 29.8 \\
LFSER & 41.4 & 44.6 \\
\hline
\end{tabular}

Note that the computed targets for two indicators are lower than their actual values. This issue will be addressed later in this paper.

Computed targets for all provinces and all indicators are presented in Table B3 in Appendix B. 13

A few points about the proposed procedure are notable at this stage. The method relies on the computation of the targets from the actual values belonging to a homogenous group. Hence, it 
considers the question of capacity implicitly by including homogenous group members and excluding the heterogeneous provinces from the computation of targets.

However, the exclusion of those provinces which are at a lower level of development from the computation of targets may be arguable. Generally it may be argued that the disparities between provinces are of two kinds, external and internal. By external we mean that a province may have been developed disproportionately at the expense of another province being left behind, and by internal we mean that a province may have been developed disproportionately in a few aspects at the expense of being left behind in other aspects. Therefore one can suggest that computing the targets on the basis of the actual values belonging to better off provinces may be arguable. However, as homogeneity is based on all selected indicators of social and economic aspects one hopes that the extent of this bias in the computed targets would be limited.

\section{A project selection model for reducing regional disparities}

If the government would wish to pursue the policy of reducing regional disparities, the targets computed by the above procedure would be helpful in formulating appropriate policies in a variety of ways. One approach consists of including these targets in a mixed integer programming zero one project selection model in the form of a set of constraints. For example a cost minimisation model of this form for a single province may look as follow:

Minimise $\quad \boldsymbol{Z}=\sum_{j=1}^{1} \sum_{i=1}^{n_{1}} \boldsymbol{c}_{i j} \boldsymbol{x}_{i j}$

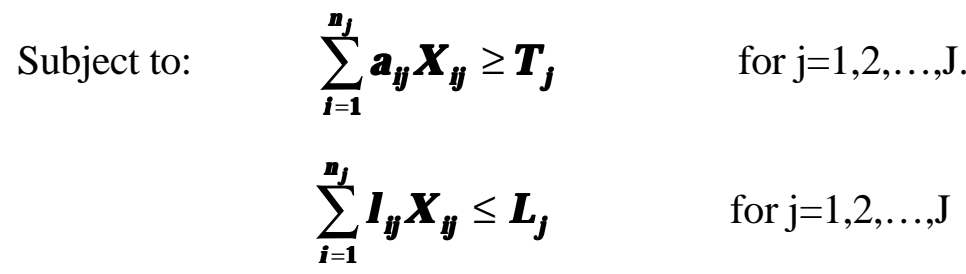

\footnotetext{
1 , if the $\mathrm{i}^{\text {th }}$ project related to the $\mathrm{j}^{\text {th }}$ indicator is selected,

$X_{i j}=$

0 , if the $\mathrm{i}^{\text {th }}$ project related to the $\mathrm{j}^{\text {th }}$ indicator is not selected.
}

Where:

$\mathrm{c}_{\mathrm{ij}}=$ the cost of implementing project i related to indicator $\mathrm{j}$,

$\mathrm{X}_{\mathrm{ij}}=$ the $\mathrm{i}^{\text {th }}$ project related to the $\mathrm{j}^{\text {th }}$ indicator, 
$\mathrm{a}_{\mathrm{ij}}=$ the contribution of the $\mathrm{i}^{\text {th }}$ project to the $\mathrm{j}^{\mathrm{th}}$ to the target set for indicator $\mathrm{j}$,

$\mathrm{T}_{\mathrm{j}}=$ the proposed target for the $\mathrm{j}^{\text {th }}$ indicator for the province under consideration,

$\mathrm{l}_{\mathrm{ij}}=$ human resources required by the $\mathrm{i}^{\text {th }}$ project related to indicator $\mathrm{j}$,

$\mathrm{L}_{\mathrm{j}}=$ available human resources of the kind required by projects related to indicator $\mathrm{j}$,

$\mathrm{n}_{\mathrm{j}}=$ the number of projects related to indicator $\mathrm{j}$,

$\mathrm{J}=$ the number of selected indicators.

Further limitations related to other scarce resources can be included in the model in the form of appropriate constraints. The above model can be used for individual provinces. However, considering provinces individually may be undesirable as resources are transferable within a country amongst various provinces. Assuming such transferability in general we may formulate the following project selection model for all provinces.

Minimise $\quad Z=\sum_{r=1}^{R} \sum_{j=1}^{L} \sum_{i=1}^{n_{j}^{r}} c_{i j}^{r} X_{i j}^{r}$

Subject to $\quad \sum_{i=1}^{n_{j}^{r}} a_{i j}^{r} X_{i j}^{r} \geq \boldsymbol{T}_{j}^{r} \quad$ for $\mathrm{r}=1,2, \ldots, \mathrm{R} ;$ and $\mathrm{J}=1,2, \ldots, \mathrm{J}$.

$$
\sum_{r=1}^{R} \sum_{i=1}^{n_{L}^{r}} I_{i j}^{r} X_{i j}^{r} \leq L_{j} \quad \quad \text { for } \mathrm{j}=1,2, \ldots, \mathrm{J} .
$$

\footnotetext{
1 , if the $\mathrm{i}^{\text {th }}$ project related to the $\mathrm{j}^{\text {th }}$ indicator is selected,

$X_{i j}^{r}=$

0 , if the $\mathrm{i}^{\text {th }}$ project related to the $\mathrm{j}^{\text {th }}$ indicator is not selected.
}

Where

$\boldsymbol{c}_{i j}^{r}=$ the cost of implementing project i related to indicator $\mathrm{j}$ in the $\mathrm{r}^{\text {th }}$ province,

$\boldsymbol{X}_{i j}^{r}=$ the $\mathrm{i}^{\text {th }}$ project related to the $\mathrm{j}^{\text {th }}$ indicator for the $\mathrm{r}^{\text {th }}$ province,

$\mathbf{a}_{i j}^{r}=$ the contribution of the $\mathrm{i}^{\text {th }}$ project to the $\mathrm{j}^{\text {th }}$ target set for indicator $\mathrm{j}$ in province $\mathrm{r}$,

$\boldsymbol{T}_{j}^{r}=$ the proposed target for the $\mathrm{j}^{\text {th }}$ indicator for the $\mathrm{r}^{\text {th }}$ province,

$I_{i j}^{r}=$ human resources required by the $i^{\text {th }}$ project related to indicator $\mathrm{j}$ for province $\mathrm{r}$,

$\boldsymbol{L}_{\boldsymbol{j}}=$ available human resources of the kind required by projects related to indicator $\mathrm{j}$,

$\boldsymbol{n}_{\boldsymbol{j}}^{\boldsymbol{r}}=$ the number of projects related to indicator $\mathrm{j}$ for province $\mathrm{r}$, 
$\boldsymbol{J}=$ the number of selected indicators.

$\boldsymbol{R}=$ the number of provinces.

The above model assumes inter-regional mobility of human resources. Any limitation to this assumption can be introduced into the model easily. In addition other constraints related to the scarcity of other resources can be easily added to the model.

\section{Adjusting the computed targets}

As we discussed before the main purpose of the suggested procedure is the determination of $\boldsymbol{T}_{j} \boldsymbol{r}$ for the above model or other purposes. However, the targets computed by the above procedure might not be attainable for different reasons of which the most important one is usually budget and other resource limitations. If the policy makers for any reason are interested to consider a proportion of the computed targets in the model it would be possible to modify the first set of constraints as follow:

$\sum_{i=1}^{n_{j}^{r}} a_{i j}^{r} X_{i j}^{r} \geq \delta_{j}^{r} T_{j}^{r} \quad$, for $\mathrm{r}=1,2, \ldots, \mathrm{R} ;$ and $\mathrm{J}=1,2, \ldots, \mathrm{J}$.

where coefficient $\delta_{j}^{r}$ reflects the percentage of the computed targets to be achieved.

The determination of $\delta_{j}^{r}$ in not necessarily a decision to be made outside the model. Ideed the model may fail to have a feasible solution due to the limitation of skilled labour, budget or other reasons. In this case an appropriate choice of $\delta_{j}^{r}$ could be useful in achieving a solution for the model.

Before we suggest ways of finding $\delta_{j}^{r}$ it would be useful to make a small modification to the above set of constraints. It would also be more appropriate to replace the computed targets, $\mathrm{T}_{\mathrm{j}}^{\mathrm{r}}$, with a change in the level of (the concept reflected by) the indicator as follows:

$\sum_{i=1}^{\mathbf{n}_{j}^{r}} \mathbf{a}_{i j}^{r} \boldsymbol{X}_{i j}^{r} \geq \delta_{j}^{r} \boldsymbol{M}_{j}^{r} \quad$, for $\mathrm{r}=1,2, \ldots, \mathrm{R} ;$ and $\mathrm{J}=1,2, \ldots, \mathrm{J}$

where $M_{j}^{r}$ is the amount of increase in the $j^{\text {th }}$ indicator for the $r^{\text {th }}$ province and is computed as the difference between the computed targets, $\mathrm{T}_{\mathrm{j}}^{\mathrm{r}}$, and the present actual value of the indicator 
(Table B1). The nature of the model now changes appropriately. That is, the least cost set of feasible projects are selected in order to achieve the adjusted amount of increases in the level of indicators.

We now attend to computing $\delta_{\mathrm{j}}^{r}$. There are a number of ways of finding these coefficients. One usual way is to assume that the policy maker would provide these values. However, we can propose a number of ways for computing these coefficients.

(i) One simple way is to reduce $M_{j}^{r}$ by a constant percentage (for example reducing all $M_{j}^{r}$ by $10 \%)$.

(ii) Another way is to reduce $\mathrm{M}_{\mathrm{j}}^{\mathrm{r}}$ for the $\mathrm{j}^{\mathrm{th}}$ indicator (for all provinces) by a certain ratio.

(iii) A more accurate way is to reduce the change in targets for each province with respect to the overall position of the province on the development scale RHDI. That is, setting $\delta_{\mathrm{j}}^{\mathrm{r}}$ for the province with the lowest ranking equal to 1 and scaling $\delta_{\mathrm{j}}^{\mathrm{r}}$ for other provinces proportionately according to their relative RHDI. It must be pointed out that in this method we are in effect adjusting $\delta^{r}$ rather than $\delta_{\mathrm{j}}^{r}$. In other words the weights for all indicators belonging to province $r$ are the same.

(iv) An even more accurate method, deals with a set of weights which vary not only with respect to different provinces but also with respect to different indicators. They may be obtained from the detailed elements of the RHDI. These are all $\left(Z_{i j}-Z_{o j}\right)$ for province $\mathrm{i}$ (as computed from equation 5). For indicator $\mathrm{j}$ for the province furthest away from the ideal province put $\delta_{\mathrm{j}}^{\mathrm{r}}=1$ and assign values to other $\delta_{\mathrm{j}}^{\mathrm{r}}$ proportionately.

In applying the last method sometimes $M_{j}^{r}$ are negative implying a reduction in the level of indicators. This happens when the computed targets $T_{j}^{r}$ is less than the actual value for the indicator concerned. In such cases, if the policy maker does not wish to reduce the level of the indicator it is appropriate to put the relevant $\delta_{\mathrm{j}}^{\mathrm{r}}=0$.

Table 4 displays the computed adjusted targets for indicator 2, adult literacy, for all provinces employing method (iv) explained above. 
Table 4. Computed targets for adult literacy (indicator 2) for all provinces

\begin{tabular}{lccccc}
\hline & Target & $\begin{array}{c}\text { Actual } \\
\text { value }\end{array}$ & $\mathrm{M}_{2}^{r}$ & $\delta_{j}^{r}$ & $\mathrm{M}_{2}^{r} \mathbf{9} \delta_{j}^{r}$ \\
1. Ardebil & 68.9 & 63.2 & 5.7 & 0.59 & 3.4 \\
2. Booshehr & 72.4 & 72.5 & -0.1 & 0.33 & $0.0^{*}$ \\
3. Chahar Mahal B. & 71.2 & 67.2 & 4.0 & 0.48 & 1.9 \\
4. East Azarbayjan & 70.5 & 67.5 & 3.0 & 0.47 & 1.4 \\
5. Fars & 76.4 & 74.7 & 1.7 & 0.27 & 0.5 \\
6. Gilan & 73.7 & 72.6 & 1.1 & 0.33 & 0.3 \\
7. Hamedan & 69.8 & 68.1 & 1.7 & 0.45 & 0.8 \\
8. Hormozgan & 69.6 & 63.3 & 6.3 & 0.58 & 3.7 \\
9. Ilam & 71.0 & 67 & 4.0 & 0.48 & 1.9 \\
10. Isfahan & 72.6 & 79.5 & -6.9 & 0.14 & $0.0^{*}$ \\
11. Kerman & 71.3 & 70.5 & 0.8 & 0.39 & 0.3 \\
12. Kermanshah & 71.5 & 68.1 & 3.4 & 0.45 & 1.5 \\
13. Khoozestan & 71.0 & 69.2 & 1.8 & 0.42 & 0.8 \\
14. Khorasan & 70.2 & 73.9 & -3.7 & 0.30 & $0.0^{*}$ \\
15. Kohkilooyeh \& B. A. & 66.6 & 61.9 & 4.7 & 0.62 & 2.9 \\
16. Kordestan & 64.1 & 56.9 & 7.2 & 0.76 & 5.4 \\
17. Lorestan & 70.1 & 65 & 5.1 & 0.54 & 2.8 \\
18. Markasi & 77.2 & 71.7 & 5.5 & 0.36 & 1.9 \\
19. Mazandaran & 74.1 & 72 & 2.1 & 0.35 & 0.7 \\
20. Qom & 80.1 & 75.4 & 4.6 & 0.25 & 1.2 \\
21. Semnan & 79.0 & 79.5 & -0.5 & 0.14 & $0.0^{*}$ \\
22. Sistan \& B. & 54.6 & 48.1 & 6.5 & 1.00 & 6.5 \\
23. Tehran & 84.7 & 84.7 & 0.0 & 0.00 & 0.0 \\
24. West Azarbayjan & 66.9 & 61.1 & 5.8 & 0.64 & 3.7 \\
25. Yazd & 78.7 & 77.9 & 0.8 & 0.19 & 0.1 \\
26. Zanjan & 68.1 & 65.2 & 2.9 & 0.53 & 1.5 \\
\hline is & & & & &
\end{tabular}

* $\delta_{\mathrm{j}}^{\mathrm{r}}$ is set equal to 0 as $\mathrm{M}_{\mathrm{j}}^{\mathrm{r}}$ is negative.

Using the above method we have computed the adjusted targets for all indicators and provinces. They are presented in Table B3 in Appendix B.

Finally it should be pointed out that $\delta_{\mathrm{j}}^{\mathrm{r}}$ computed by the suggested method (iv) may have other applications outside the adjustment method or project selection model outlined above. These coefficients can be computed for all indicators and provinces. It would then be possible to use them for the (proportionate) regional allocation of activities which will affect the level of indicators. However, in this approach only the concept of relativity is taken into account while our suggested procedure as outlined above takes both relativity and capacity into account in obtaining the adjusted targets for provinces. Indeed $\delta_{\mathrm{j}}^{\mathrm{r}}$ are introducing the concept of relativity into the analysis while $\mathrm{M}_{\mathrm{j}}^{\mathrm{r}}$ are addressing the question of capacity in the manner discussed above. 


\section{Summary and Conclusion}

This paper argues for the necessity of making HDI more policy oriented and operational. Judging from the historical fate of the numerous composite indices which have appeared and subsequently disappeared in recent decades it seems that if this is not done the HDI will soon suffer from the same fate.

To make the index more policy oriented at country level we should be prepared to relax some of the generality of the index which is expected from an inter-country composite index. The constituent, content and structure of the index should be more related to the policy problems specific to the country concerned. We should accept that such policy problems and hence the content of the index may be different for various countries and that the index should be tailored to the policy concerns of the country in mind, although some such policy concerns may be common in a number of countries. Indeed from a look at the various human development reports at country level it can be seen that the focus of each country's report is on the specific problems of the country and the related policies within the spirit of the concept of human development.

How this can be done is demonstrated by focusing on an important and persistent problem in the case of Iran. Regional disparities are an important policy concern in the Third Development Plan of Iran. The second part of this paper proposes a method and a model for the systematic reduction of these disparities. The proposed method develops a composite index based on sixteen operational indicators of longevity, education, health, gender, poverty and economic activity, within the spirit of HDI for ranking different provinces of Iran. It proceeds to identify homogenous groups of provinces and captures the degree of heterogeneity within these groups. The proposed method computes a set of targets for all provinces in Iran . The computation of these targets is based on three principles: equity, capacity to absorb progress and practical concerns at the national level. The computed targets are then included in a 0-1 integer programming model for project selection. 


\section{Appendix A}

\section{List of regional indicators for Iran - 1996}

1. Life expectancy, years (LE).

2. Adult literacy, percentage (AL).

3. Real consumption expenditure per capita, 1000 Rials (RCPC).

4. Percentage population with access to safe water (SFWA).

5. Percentage population with access to sanitation (SANA).

6. Real consumption expenditure per capita of the poorest 20\%, 1000 Rials (RCP20).

7. Female primary enrolment ratio (FPENR).

8. Female secondary enrolment ratio.

9. Infant survival rate (INFS).

10. Maternal survival rate (MATS).

11. Primary enrolment ratio.

12. Secondary enrolment ratio.

13. Research and development scientists and technicians per 100000 population (RDST).

14. Labour force, as a percentage of population (LF).

15. Percentage labour force in industry.

16. Percentage labour force in services.

Notes:

(i) As we require the direction of indicators to be positive we have computed infant survival rate from infant mortality rate. Similarly maternal survival rate has been computed from the rate of maternal death at birth.

(ii) Source of data is the First Human Development Report of the Islamic Republic of Iran (1999). 
Appendix B 
Table B1. Regional data for the selected indicators

\section{Province}

Indicator LE AL RCPC SFWA SANA RCP20 FPENR FSENR INFS MATS PENR SENR R\&DST LF LFIND LFSER

\begin{tabular}{|c|c|c|c|c|c|c|c|c|c|c|c|c|c|c|c|c|}
\hline 1 Ardebil & 65.7 & 63.2 & 1652 & 89.9 & 49.7 & 378 & 91.1 & 40.8 & 954.1 & 943.2 & 128.9 & 65.8 & 15 & 24.9 & 26.7 & 37.8 \\
\hline 2 Booshehr & 66.6 & 72.5 & 1493 & 96.5 & 62.5 & 441 & 95.7 & 56.4 & 957.6 & 947.2 & 116.5 & 77.5 & 32.8 & 22.5 & 20.4 & 60.6 \\
\hline 3 Chahar Mahal B. & 65.9 & 67.2 & 1437 & 98.7 & 61.8 & 391 & 96.2 & 56.3 & 955 & 934.8 & 114.7 & 76 & 15.6 & 25.6 & 44.1 & 33.9 \\
\hline 4 East Azarbayjan & 66.5 & 67.5 & 1652 & 92.2 & 62 & 461 & 93 & 50.4 & 957.2 & 952.4 & 126.3 & 70.8 & 23.3 & 28.4 & 36.4 & 38.2 \\
\hline 5 Fars & 67.5 & 74.7 & 1925 & 93.6 & 63.8 & 546 & 97.5 & 59.4 & 961.5 & 975.9 & 115.6 & 76.2 & 27.9 & 25.4 & 28.5 & 48 \\
\hline 6 Gilan & 70.3 & 72.6 & 1671 & 85.8 & 77.3 & 428 & 99.2 & 68.9 & 972.3 & 953.1 & 120.8 & 83.9 & 63.6 & 32.1 & 20.5 & 40.1 \\
\hline 7 Hamedan & 65.5 & 68.1 & 1182 & 92.7 & 53.4 & 252 & 95.7 & 77.6 & 953.4 & 979.9 & 117.8 & 68.8 & 41.3 & 26 & 29.8 & 38.4 \\
\hline 8 Hormozgan & 65.9 & 63.3 & 1585 & 86.4 & 62.3 & 403 & 91.7 & 44.4 & 954.9 & 956 & 120.2 & 63.3 & 36.3 & 21.1 & 22.4 & 53.8 \\
\hline 9 Ilam & 64 & 67 & 1409 & 95.9 & 83.8 & 435 & 93.8 & 62.4 & 947 & 943.5 & 127.6 & 87.2 & 19.9 & 22.5 & 20 & 50.9 \\
\hline 10 Isfahan & 70.3 & 79.5 & 1758 & 97.8 & 77.2 & 385 & 99 & 69.6 & 971.9 & 986.2 & 115.3 & 83 & 112.2 & 28.2 & 41.6 & 43.9 \\
\hline 11 Kerman & 65.4 & 70.5 & 1714 & 90 & 69.2 & 384 & 99.9 & 66.3 & 952.9 & 969.6 & 127.9 & 81.6 & 43.6 & 24.2 & 24.8 & 45.8 \\
\hline 12 Kermanshah & 65 & 68.1 & 1860 & 94.9 & 60.4 & 618 & 93.4 & 52.1 & 951.4 & 961.7 & 124.5 & 74.5 & 16.8 & 26.2 & 22.4 & 51.6 \\
\hline 13 Khoozestan & 66.9 & 69.2 & 1781 & 91 & 68.6 & 658 & 87.8 & 50.7 & 958.8 & 969.4 & 117.4 & 70.5 & 26.5 & 22.8 & 31.1 & 49.2 \\
\hline 14 Khorasan & 64.3 & 73.9 & 1502 & 94.2 & 54.7 & 277 & 94 & 54.2 & 948.3 & 949.8 & 122.7 & 69.9 & 24.1 & 26.4 & 29.7 & 40.9 \\
\hline 15 Kohkilooyeh \& B. A. & 63.4 & 61.9 & 1160 & 88.1 & 37.9 & 222 & 92 & 47.9 & 943.9 & 937.2 & 131.4 & 85 & 13.2 & 20.6 & 29.7 & 42.5 \\
\hline 16 Kordestan & 61.6 & 56.9 & 1389 & 95.8 & 60.7 & 485 & 84 & 35.9 & 936.3 & 900.6 & 119.5 & 61.3 & 16 & 25.6 & 28.5 & 40.1 \\
\hline 17 Lorestan & 64.6 & 65 & 1476 & 95.2 & 52.7 & 495 & 96 & 55.5 & 949.3 & 972 & 125 & 83.4 & 19 & 23.3 & 27.2 & 43.3 \\
\hline 18 Markasi & 66.7 & 71.7 & 1750 & 98.6 & 69 & 427 & 98.7 & 55.9 & 958.2 & 979.7 & 124.3 & 74.3 & 63.8 & 27 & 37.3 & 36.4 \\
\hline 19 Mazandaran & 67.4 & 72 & 1557 & 93 & 64.6 & 371 & 97.3 & 67 & 961.1 & 972.5 & 116.6 & 84.2 & 35.1 & 26.8 & 22.3 & 41.4 \\
\hline 20 Qom & 67.6 & 75.4 & 3057 & 99.5 & 83.8 & 832 & 97.5 & 59.6 & 962.1 & 993.2 & 116.5 & 76.2 & 131.3 & 23.6 & 41.7 & 50 \\
\hline 21 Semnan & 68.2 & 79.5 & 1586 & 99.4 & 82.1 & 300 & 98.8 & 73 & 964.2 & 959.1 & 110.6 & 87.6 & 89.3 & 27.1 & 26.9 & 52.1 \\
\hline 22 Sistan \& B. & 61.1 & 48.1 & 1120 & 90.6 & 41.1 & 263 & 65.5 & 25 & 934.5 & 974.8 & 111.4 & 43.4 & 21.2 & 19.4 & 22.6 & 44.8 \\
\hline 23 Tehran & 70.5 & 84.7 & 3057 & 99.8 & 85.3 & 832 & 99.9 & 77.9 & 973.1 & 976.8 & 115.6 & 91.5 & 192.8 & 27.2 & 33.7 & 61.9 \\
\hline 24 West Azarbayjan & 64.7 & 61.1 & 1439 & 91.5 & 51.4 & 393 & 77.2 & 40.1 & 951.9 & 916.2 & 112.3 & 62.4 & 4.5 & 26.9 & 24.5 & 42 \\
\hline 25 Yazd & 68.5 & 77.9 & 1771 & 99.1 & 81.2 & 316 & 97 & 71.2 & 962.8 & 991.8 & 110.1 & 81.8 & 70.1 & 29.3 & 43.5 & 42.1 \\
\hline 26 Zandjan & 65.8 & 65.2 & 1291 & 90.5 & 50.4 & 310 & 92.9 & 44.6 & 954.4 & 925.1 & 119.4 & 64.8 & 23.2 & 25 & 28.3 & 32.9 \\
\hline 0 Country & 69.2 & 72.9 & 1899 & 94.5 & 64.3 & 430 & 94.7 & 58.9 & 968.3 & 962.6 & 119.1 & 76.8 & 66.9 & 26.1 & 30.4 & 46.8 \\
\hline
\end{tabular}


Table B2. Composite distances between provinces (Matrix D)

\begin{tabular}{|c|c|c|c|c|c|c|c|c|c|c|c|c|c|c|c|c|c|c|c|}
\hline Province & 1 & 2 & 3 & 4 & 5 & 6 & 7 & 8 & 9 & 10 & 11 & 12 & 13 & 14 & 15 & 16 & 17 & 18 & 19 \\
\hline 1 Ardebil & 0.000 & 4.881 & 4.502 & 2.533 & 4.410 & 5.773 & 4.179 & 3.354 & 4.685 & 6.916 & 3.657 & 3.448 & 3.963 & 2.742 & 3.444 & 4.230 & 3.180 & 4.257 & 4.342 \\
\hline 2 Booshehr & 4.881 & 0.000 & 5.106 & 4.825 & 3.005 & 5.871 & 4.620 & 3.490 & 3.458 & 5.683 & 3.738 & 3.019 & 3.406 & 3.989 & 5.616 & 5.935 & 3.622 & 4.862 & 3.539 \\
\hline 3 Chahar Mahal B. & 4.502 & 5.106 & 0.000 & 3.221 & 4.112 & 6.268 & 3.904 & 5.658 & 5.291 & 5.020 & 4.862 & 4.772 & 4.475 & 3.345 & 5.634 & 4.962 & 3.988 & 3.201 & 4.167 \\
\hline 4 East Azarbayjan & 2.533 & 4.825 & 3.221 & 0.000 & 3.367 & 4.641 & 3.618 & 4.363 & 4.653 & 5.060 & 3.351 & 3.210 & 3.450 & 2.526 & 4.862 & 4.895 & 3.218 & 2.564 & 3.491 \\
\hline 5 Fars & 4.410 & 3.005 & 4.112 & 3.367 & 0.000 & 4.421 & 3.658 & 3.973 & 4.440 & 3.954 & 3.111 & 2.765 & 2.294 & 3.534 & 6.083 & 6.382 & 3.276 & 3.139 & 2.177 \\
\hline 6 Gilan & 5.773 & 5.871 & 6.268 & 4.641 & 4.421 & 0.000 & 5.247 & 6.048 & 6.166 & 4.874 & 4.569 & 5.448 & 5.475 & 5.554 & 7.603 & 8.202 & 5.963 & 5.155 & 3.505 \\
\hline 7 Hamedan & 4.179 & 4.620 & 3.904 & 3.618 & 3.658 & 5.247 & 0.000 & 4.610 & 4.917 & 5.102 & 3.371 & 4.326 & 4.418 & 2.755 & 5.052 & 6.021 & 3.409 & 3.563 & 2.778 \\
\hline 8 Hormozgan & 3.354 & 3.490 & 5.658 & 4.363 & 3.973 & 6.048 & 4.610 & 0.000 & 4.363 & 6.941 & 3.660 & 3.563 & 2.981 & 4.024 & 4.494 & 5.233 & 3.872 & 5.380 & 4.435 \\
\hline 9 Ilam & 4.685 & 3.458 & 5.291 & 4.653 & 4.440 & 6.166 & 4.917 & 4.363 & 0.000 & 6.650 & 2.920 & 3.258 & 4.342 & 4.007 & 4.848 & 5.344 & 3.183 & 4.792 & 4.127 \\
\hline 10 Isfahan & 6.916 & 5.683 & 5.020 & 5.060 & 3.954 & 4.874 & 5.102 & 6.941 & 6.650 & 0.000 & 5.323 & 5.980 & 5.301 & 5.663 & 8.342 & 8.751 & 5.944 & 3.573 & 4.126 \\
\hline 11 Kerman & 3.657 & 3.738 & 4.862 & 3.351 & 3.111 & 4.569 & 3.371 & 3.660 & 2.920 & 5.323 & 0.000 & 2.942 & 3.652 & 3.055 & 4.387 & 6.123 & 2.548 & 3.515 & 2.715 \\
\hline 12 Kermanshah & 3.448 & 3.019 & 4.772 & 3.210 & 2.765 & 5.448 & 4.326 & 3.563 & 3.258 & 5.980 & 2.942 & 0.000 & 2.796 & 3.155 & 5.086 & 4.875 & 2.384 & 3.833 & 3.460 \\
\hline 13 Khoozestan & 3.963 & 3.406 & 4.475 & 3.450 & 2.294 & 5.475 & 4.418 & 2.981 & 4.342 & 5.301 & 3.652 & 2.796 & 0.000 & 3.983 & 5.660 & 5.528 & 3.400 & 4.011 & 3.664 \\
\hline 14 Khorasan & 2.742 & 3.989 & 3.345 & 2.526 & 3.534 & 5.554 & 2.755 & 4.024 & 4.007 & 5.663 & 3.055 & 3.155 & 3.983 & 0.000 & 4.023 & 4.370 & 2.743 & 3.206 & 3.257 \\
\hline 15 Kohkilooyeh \& B. A. & 3.444 & 5.616 & 5.634 & 4.862 & 6.083 & 7.603 & 5.052 & 4.494 & 4.848 & 8.342 & 4.387 & 5.086 & 5.660 & 4.023 & 0.000 & 5.254 & 3.670 & 6.009 & 5.654 \\
\hline 16 Kordestan & 4.230 & 5.935 & 4.962 & 4.895 & 6.382 & 8.202 & 6.021 & 5.233 & 5.344 & 8.751 & 6.123 & 4.875 & 5.528 & 4.370 & 5.254 & 0.000 & 5.008 & 6.165 & 6.472 \\
\hline 17 Lorestan & 3.180 & 3.622 & 3.988 & 3.218 & 3.276 & 5.963 & 3.409 & 3.872 & 3.183 & 5.944 & 2.548 & 2.384 & 3.400 & 2.743 & 3.670 & 5.008 & 0.000 & 3.407 & 3.229 \\
\hline 18 Markasi & 4.257 & 4.862 & 3.201 & 2.564 & 3.139 & 5.155 & 3.563 & 5.380 & 4.792 & 3.573 & 3.515 & 3.833 & 4.011 & 3.206 & 6.009 & 6.165 & 3.407 & 0.000 & 3.288 \\
\hline 19 Mazandaran & 4.342 & 3.539 & 4.167 & 3.491 & 2.177 & 3.505 & 2.778 & 4.435 & 4.127 & 4.126 & 2.715 & 3.460 & 3.664 & 3.257 & 5.654 & 6.472 & 3.229 & 3.288 & 0.000 \\
\hline 20 Qom & 7.763 & 6.408 & 6.640 & 6.411 & 4.854 & 7.441 & 7.311 & 7.265 & 7.120 & 4.873 & 6.345 & 5.935 & 5.161 & 7.133 & 9.358 & 8.843 & 6.555 & 5.124 & 6.330 \\
\hline 21 Semnan & 6.809 & 3.942 & 5.127 & 5.522 & 3.682 & 4.890 & 4.847 & 6.203 & 5.132 & 3.165 & 4.769 & 5.226 & 5.171 & 5.107 & 7.813 & 7.867 & 5.458 & 4.438 & 3.348 \\
\hline 22 Sistan \& B. & 6.824 & 8.203 & 8.484 & 8.210 & 8.745 & 11.037 & 7.798 & 6.332 & 8.512 & 11.208 & 8.710 & 7.818 & 7.456 & 7.382 & 7.129 & 5.884 & 7.544 & 9.109 & 8.896 \\
\hline 23 Tehran & 9.861 & 7.417 & 8.798 & 8.416 & 6.470 & 7.503 & 8.937 & 9.124 & 8.534 & 5.378 & 7.825 & 7.695 & 7.377 & 8.984 & 11.222 & 11.133 & 8.587 & 7.247 & 7.406 \\
\hline 24 West Azarbayjan & 3.758 & 5.147 & 4.821 & 4.402 & 5.288 & 6.752 & 5.133 & 4.291 & 5.771 & 7.758 & 5.821 & 4.619 & 4.556 & 4.036 & 5.415 & 3.172 & 4.997 & 5.977 & 5.255 \\
\hline 25 Yazd & 6.969 & 5.794 & 4.401 & 5.015 & 4.012 & 5.469 & 4.683 & 7.055 & 6.526 & 2.010 & 5.468 & 5.937 & 5.360 & 5.290 & 8.313 & 8.218 & 5.820 & 3.549 & 4.078 \\
\hline 26 Zanjan & 2.167 & 4.932 & 3.556 & 3.016 & 4.519 & 5.713 & 3.703 & 3.870 & 5.161 & 6.653 & 4.341 & 4.355 & 4.346 & 2.625 & 4.020 & 3.933 & 3.819 & 4.438 & 4.129 \\
\hline
\end{tabular}

* This distance is larger than the critical minimum distance, $\mathrm{d}(+)$, of 4.462 . 


\begin{tabular}{|c|c|c|c|c|c|c|c|c|c|}
\hline Region & 20 & 21 & 22 & 23 & 24 & 25 & 26 & $\begin{array}{l}\text { Minimum } \\
\text { Distance }\end{array}$ & $\begin{array}{c}\text { Closest } \\
\text { Neighbour }\end{array}$ \\
\hline 1 Ardebil & 7.763 & 6.809 & 6.824 & 9.861 & 3.758 & 6.969 & 2.167 & 2.167 & 26 \\
\hline 2 Booshehr & 6.408 & 3.942 & 8.203 & 7.417 & 5.147 & 5.794 & 4.932 & 3.005 & 5 \\
\hline 3 Chahar Mahal B. & 6.640 & 5.127 & 8.484 & 8.798 & 4.821 & 4.401 & 3.556 & 3.201 & 18 \\
\hline 4 East Azarbayjan & 6.411 & 5.522 & 8.210 & 8.416 & 4.402 & 5.015 & 3.016 & 2.526 & 14 \\
\hline 5 Fars & 4.854 & 3.682 & 8.745 & 6.470 & 5.288 & 4.012 & 4.519 & 2.177 & 19 \\
\hline 6 Gilan & 7.441 & 4.890 & 11.037 & 7.503 & 6.752 & 5.469 & 5.713 & 3.505 & 19 \\
\hline 7 Hamedan & 7.311 & 4.847 & 7.798 & 8.937 & 5.133 & 4.683 & 3.703 & 2.755 & 14 \\
\hline 8 Hormozgan & 7.265 & 6.203 & 6.332 & 9.124 & 4.291 & 7.055 & 3.870 & 2.981 & 13 \\
\hline 9 Ilam & 7.120 & 5.132 & 8.512 & 8.534 & 5.771 & 6.526 & 5.161 & 2.920 & 11 \\
\hline 10 Isfahan & 4.873 & 3.165 & 11.208 & 5.378 & 7.758 & 2.010 & 6.653 & 2.010 & 25 \\
\hline 11 Kerman & 6.345 & 4.769 & 8.710 & 7.825 & 5.821 & 5.468 & 4.341 & 2.548 & 17 \\
\hline 12 Kermanshah & 5.935 & 5.226 & 7.818 & 7.695 & 4.619 & 5.937 & 4.355 & 2.384 & 17 \\
\hline 13 Khoozestan & 5.161 & 5.171 & 7.456 & 7.377 & 4.556 & 5.360 & 4.346 & 2.294 & 5 \\
\hline 14 Khorasan & 7.133 & 5.107 & 7.382 & 8.984 & 4.036 & 5.290 & 2.625 & 2.526 & 4 \\
\hline 15 Kohkilooyeh \& B. A. & 9.358 & 7.813 & 7.129 & 11.222 & 5.415 & 8.313 & 4.020 & 3.444 & 1 \\
\hline 16 Kordestan & 8.843 & 7.867 & 5.884 & 11.133 & 3.172 & 8.218 & 3.933 & 3.172 & 24 \\
\hline 17 Lorestan & 6.555 & 5.458 & 7.544 & 8.587 & 4.997 & 5.820 & 3.819 & 2.384 & 12 \\
\hline 18 Markasi & 5.124 & 4.438 & 9.109 & 7.247 & 5.977 & 3.549 & 4.438 & 2.564 & 4 \\
\hline 19 Mazandaran & 6.330 & 3.348 & 8.896 & 7.406 & 5.255 & 4.078 & 4.129 & 2.177 & 5 \\
\hline 20 Qom & 0.000 & 5.827 & 11.186 & 4.031 & 8.642 & 5.317 & 8.148 & 4.031 & 23 \\
\hline 21 Semnan & 5.827 & 0.000 & 10.547 & 5.816 & 6.925 & 3.209 & 6.317 & 3.165 & 10 \\
\hline 22 Sistan \& B. & 11.186 & 10.547 & 0.000 & 13.755 & 5.549 & 10.640 & 6.810 & 5.549 & 24 \\
\hline 23 Tehran & 4.031 & 5.816 & 13.755 & 0.000 & 10.487 & 6.422 & 10.112 & 4.031 & 20 \\
\hline 24 West Azarbayjan & 8.642 & 6.925 & 5.549 & 10.487 & 0.000 & 7.325 & 3.057 & 3.057 & $26^{*}$ \\
\hline 25 Yazd & 5.317 & 3.209 & 10.640 & 6.422 & 7.325 & 0.000 & 6.505 & 2.010 & 10 \\
\hline 26 Zanjan & 8.148 & 6.317 & 6.810 & 10.112 & 3.057 & 6.505 & 0.000 & 2.167 & 1 \\
\hline
\end{tabular}


Table B3. Computed targets for all provinces and all indicators

\begin{tabular}{|c|c|c|c|c|c|c|c|c|c|c|c|c|c|c|c|c|c|}
\hline \multirow[t]{2}{*}{ Province } & \multirow[b]{2}{*}{ Indicator } & \multirow[b]{2}{*}{$\mathbf{L E}$} & \multirow[b]{2}{*}{$\mathbf{A L}$} & \multirow[b]{2}{*}{ RCPC } & \multirow[b]{2}{*}{ SFWA } & \multirow[b]{2}{*}{ SANA } & \multirow[b]{2}{*}{ RCP20 } & \multirow[b]{2}{*}{ FPENR } & \multirow[b]{2}{*}{ FSENR } & \multirow[b]{2}{*}{ INFS } & \multirow[b]{2}{*}{ MATS } & \multirow[b]{2}{*}{ PENR } & \multirow[b]{2}{*}{ SENR } & \multirow[b]{2}{*}{ R\&DST } & \multirow[b]{2}{*}{$\mathbf{L F}$} & \multirow[b]{2}{*}{ LFIND } & \multirow[b]{2}{*}{ LFSER } \\
\hline & & & & & & & & & & & & & & & & & \\
\hline 1 Ardebil & & 66.0 & 68.9 & 1636.3 & 92.6 & 60.9 & 439.2 & 94.7 & 56.2 & 955.1 & 965.2 & 122.3 & 73.6 & 31.1 & 25.2 & 28.2 & 43.7 \\
\hline 2 Booshehr & & 66.7 & 72.4 & 1702.3 & 94.1 & 67.3 & 474.0 & 95.8 & 60.7 & 958.2 & 965.1 & 118.4 & 78.9 & 38.9 & 25.0 & 25.2 & 49.8 \\
\hline 3 Chahar Mahal B. & & 66.4 & 71.2 & 1633.8 & 95.6 & 63.7 & 410.5 & 96.2 & 58.7 & 956.7 & 966.1 & 119.4 & 77.1 & 34.9 & 26.5 & 33.6 & 40.5 \\
\hline 4 East Azarbayjan & & 66.5 & 70.5 & 1748.4 & 93.3 & 65.4 & 495.0 & 95.4 & 57.4 & 957.3 & 968.7 & 121.8 & 76.0 & 33.9 & 25.8 & 29.0 & 44.4 \\
\hline 5 Fars & & 67.8 & 76.4 & 1702.3 & 99.0 & 77.4 & 347.7 & 98.2 & 66.7 & 961.7 & 976.9 & 115.0 & 81.2 & 74.4 & 27.8 & 35.9 & 43.5 \\
\hline 6 Gilan & & 68.9 & 73.7 & 1798.0 & 89.7 & 70.6 & 487.0 & 98.4 & 64.2 & 966.9 & 964.5 & 118.2 & 80.1 & 45.8 & 28.8 & 24.5 & 44.1 \\
\hline 7 Hamedan & & 66.0 & 69.8 & 1621.5 & 94.0 & 61.8 & 443.6 & 95.4 & 58.7 & 955.2 & 965.2 & 121.2 & 75.5 & 30.6 & 25.6 & 30.3 & 42.5 \\
\hline 8 Hormozgan & & 65.9 & 69.6 & 1642.0 & 93.5 & 64.5 & 459.7 & 94.9 & 56.2 & 954.9 & 962.5 & 122.1 & 76.1 & 30.8 & 24.7 & 26.9 & 46.7 \\
\hline 9 Ilam & & 66.5 & 71.0 & 1657.4 & 94.7 & 66.7 & 493.6 & 95.1 & 59.1 & 957.3 & 966.1 & 119.8 & 79.6 & 36.3 & 24.7 & 26.7 & 48.6 \\
\hline 10 Isfahan & & 70.3 & 72.6 & 1671 & 85.8 & 77.3 & 428 & 99.2 & 68.9 & 972.3 & 953.1 & 120.8 & 83.9 & 63.6 & 32.1 & 20.5 & 40.1 \\
\hline 11 Kerman & & 66.2 & 71.3 & 1812.3 & 94.3 & 65.6 & 493.8 & 97.4 & 58.4 & 956.0 & 971.7 & 123.1 & 76.7 & 38.0 & 25.7 & 28.3 & 45.5 \\
\hline 12 Kermanshah & & 66.4 & 71.5 & 1845.0 & 95.7 & 64.4 & 530.3 & 96.5 & 55.8 & 957.0 & 972.4 & 121.5 & 75.0 & 36.2 & 26.2 & 29.4 & 45.3 \\
\hline 13 Khoozestan & & 66.5 & 71.0 & 1764.5 & 93.5 & 65.9 & 500.7 & 95.8 & 58.6 & 957.3 & 971.5 & 121.1 & 76.9 & 35.6 & 25.4 & 27.7 & 45.4 \\
\hline 14 Khorasan & & 65.9 & 70.2 & 1647.2 & 94.1 & 64.7 & 464.8 & 95.2 & 57.3 & 954.8 & 963.1 & 122.2 & 77.3 & 30.3 & 25.0 & 27.3 & 46.0 \\
\hline 15 Kohkilooyeh \& B. A. & & 64.9 & 66.6 & 1465.8 & 91.3 & 52.4 & 344.3 & 94.3 & 51.6 & 950.5 & 949.5 & 125.9 & 75.1 & 23.0 & 24.1 & 27.7 & 40.5 \\
\hline 16 Kordestan & & 64.4 & 64.1 & 1454.6 & 92.4 & 53.4 & 368.6 & 87.8 & 43.1 & 949.0 & 927.0 & 120.6 & 64.8 & 16.6 & 25.8 & 27.5 & 38.7 \\
\hline 17 Lorestan & & 66.3 & 70.1 & 1689.8 & 93.9 & 63.6 & 489.0 & 95.5 & 57.1 & 956.4 & 966.7 & 121.6 & 77.0 & 32.1 & 25.2 & 27.8 & 46.1 \\
\hline 18 Markasi & & 68.4 & 77.2 & 1716.3 & 98.7 & 77.4 & 357.0 & 98.4 & 67.4 & 964.3 & 979.2 & 115.1 & 81.7 & 83.9 & 27.9 & 37.3 & 43.6 \\
\hline 19 Mazandaran & & 67.7 & 74.1 & 1732.4 & 94.7 & 71.6 & 419.4 & 97.9 & 64.8 & 961.8 & 972.2 & 118.4 & 80.8 & 58.0 & 27.4 & 29.8 & 44.6 \\
\hline 20 Qom & & 69.1 & 80.1 & 3057.0 & 99.7 & 84.6 & 832.0 & 98.7 & 68.8 & 967.6 & 985.0 & 116.1 & 83.9 & 162.1 & 25.4 & 37.7 & 56.0 \\
\hline 21 Semnan & & 69.0 & 79.0 & 1705.0 & 98.8 & 80.2 & 333.7 & 98.3 & 71.3 & 966.3 & 979.0 & 112.0 & 84.1 & 90.5 & 28.2 & 37.3 & 46.0 \\
\hline 22 Sistan \& B.* & & 62.9 & 54.6 & 1279.5 & 91.05 & 46.25 & 328 & 71.35 & 32.55 & 943.2 & 945.5 & 111.85 & 52.9 & 12.85 & 23.15 & 23.55 & 43.4 \\
\hline 23 Tehran & & 70.5 & 84.7 & 3057 & 99.8 & 85.3 & 832 & 99.9 & 77.9 & 973.1 & 976.8 & 115.6 & 91.5 & 192.8 & 27.2 & 33.7 & 61.9 \\
\hline 24 West Azarbayjan & & 65.7 & 66.9 & 1565.7 & 91.0 & 55.4 & 384.5 & 90.7 & 47.3 & 954.2 & 944.4 & 119.9 & 67.1 & 21.8 & 25.0 & 26.7 & 42.6 \\
\hline 25 Yazd & & 69.4 & 78.7 & 1764.5 & 98.5 & 79.2 & 350.5 & 98.0 & 70.4 & 967.4 & 989.0 & 112.7 & 82.4 & 91.2 & 28.8 & 42.6 & 43.0 \\
\hline 26 Zanjan & & 65.8 & 68.1 & 1572.2 & 92.9 & 59.9 & 417.3 & 94.4 & 55.1 & 954.5 & 958.9 & 122.0 & 72.9 & 29.5 & 25.2 & 29.4 & 41.8 \\
\hline
\end{tabular}

* As this province is an outlier and does not have a close neighbour, its targets have been computed from its closest

province (West Azarbayjan) though the distance between them is above the minimum critical distance. 


\section{References}

Ahluwalia, M. S. (1976) 'Income inequality: Some dimensions of the problem'. In Chenery et al. (1976).

Chenery, H. et al. (1976) Redistribution With Growth, Oxford University Press, Oxford.

Desai, M. (1993) 'Income and Alternative Measures of Well-Being', in D. G. Westendorff and D. Ghai (Eds), Monitoring Social Progress in the 1990s, United Nations Research Institute for Social Development, Avebury, Aldershot.

Drewnowski, J. and Scott, W. (1966) The Level of Living Index, United Nations Research Institute for Social Development, Report No. 4, United Nations, Geneva.

Fukuda-Parr, S., Haq, K. and Jolly R. (2000) 'Editors' Introduction', Journal of Human Development 1(1).

Plan and Budget Organisation of the Islamic Republic of Iran and United Nations (1999) Human Development Report of the Islamic Republic of Iran 1999, Plan and Budget Organisation of the Government of Iran and the United Nations, Tehran.

Haq, M.u. (1995) Reflections on Human Development, Oxford University Press, Oxford.

Hicks, N. and Streeten, P. (1979), 'Indicators of Development: the Search for a Basic Needs Yardstick', World Development, Vol. 7.

McGranahan, D.V. et al. (1972) Contents and Measurements of Socio-economic Development, Praeger, New York

McGranahan, D.V., Pizarro, P. and Richard, C. (1985) Measurement and Analysis of SociEconomic Development, United Nations Research Institute for Social Development, Geneva.

Morris, M.D. (1979) Measuring the Condition of the World's Poor: The Physical Quality of Life Index, Pergamon, New York.

Noorbakhsh, F. (1998a) ‘A Modified Human Development Index’, World Development, 26(3).

Noorbakhsh, F. (1998b) 'The Human Development Index: Some Technical Issues and Alternative Indices', Journal of International Development, 10(5).

Seers, D. (1972) 'What Are We Trying to Measure?', Journal of Development Studies, 8(3).

Sen, A. (1984) Resources, Values and Development, Basil Blackwell, Oxford.

Sen, A. (1988) 'The Concept of Development'. Chapter 1 in H. Chenery and T.N. Srinivasan (Eds), Handbook of Development Economics, (Volume 1), Elsevier Science Publisher, Amesterdam. 
Sen, A. (1990) 'Development as capability Expansion', Chapter 2 in K.Griffin and J. Knight Human Development and the International Development Strategy for the 1990s, Macmillan, London.

Sen, A. (2000) 'A decade of Human Development', Journal of Human Development, 1(1).

Srinivasan, T.N. (1994) 'Human Development: A New Paradigm or Reinvention of the Wheel?', American Economic Review, Papers and Proceedings, 84 (2).

Streeten, P., Burki, J.S., Haq, M.u., Hicks, N. and Stewart, F. (1981) First Things first: Meeting basic human needs in developing countries, Oxford University Press, New York.

Streeten, P. (1994) 'Human Development: Means and Ends', American Economic Review, Papers and Proceedings, 84(2).

Streeten, P. (2000) 'Looking Ahead: areas of future research in human development', Journal of Human Development, 1(1).

United Nations (1954) 'Report on International Definition and Measurement of Standards and Levels of Living', United Nations, New York.

United Nations Economic and Social Council Commission for Social Development (1969) Social Policy and Planning in National Development: Report of the Meeting of Experts on Social Policy and Planning, held in Stockholm from 1 to 10 September, 1969, United Nations, Geneva.

United Nations Development Programme (1999) Human Development Report 1999,. Oxford University Press, Oxford. [Also the same publication for 1990 to 1998].

Ward, M. (1999) Income and Well-Being:Identifying Measures of Human Progress, Paper presented at the First Global Forum On Human Development, 29-31 July 1999, United Nations Headquarters, New York. 


\section{Notes}

\footnotetext{
${ }^{1}$ For a brief history of such attempt see, for example, Noorbakhsh (1998a), (1998b) and Ward (1999).

2 The debate on the concept of development, however, continued, see for example Sen (1988; 1990); Streeten (1994); Srinivasan (1994) and Haq (1995).
}

3 Amongst the early attempts we may refer to the levels of living index (Drewnowski et al. 1966) and development index (McGranahan et al. 1972). Another measure, developed later, excluded the income component altogether. The physical quality of life index (PQLI) had three social components: infant mortality rate, life expectancy and adult literacy (Morris 1979). For one such attempt in the 80s see McGranahan et al 1985.

${ }^{4}$ For Streeten 1995 see the introductory chapter in Haq 1995.

${ }^{5}$ According to S. Fakuda-Parr, K. Haq and R. Jolly (2000) in recent years 260 national and regional human development reports in 120 countries have been published.

6 A number of papers presented in the First Global Forum on Human Development, 29-31 July 1999, New York, United Nations Development Programme emphasised this point; in particular see Streeten (2000), Sen (2000) and Ranis and Stewart (2000).

7 "Yes, it is crucial to have economic growth...But the real issues as we go forward , are the issues of equity and social justice..." As quoted by S. Fakuda-Parr, K. Haq and R. Jolly (2000) from a recent speech by the President of the World Bank.

${ }^{8}$ G. Ranis and F. Stewart (2000) term these two kinds of poverty as private income poverty and social income poverty. The same concept is regarded by the US Bureau of Census and the Luxembourg Income Studies as a comprehensive definition of income to include the total consumption of population (see Ward 1999).

${ }^{9}$ There are a number of issues involved in the selection of indicators, including their relevance, relative importance and possible overlaps. As mentioned in the text such issues are beyond the scope of this article.

${ }^{10}$ Non-availability of data at regional level was a limiting factor in this selection.

${ }^{11}$ Consider a vector $\left(X_{i j}-\bar{X}_{j}\right)$ containing deviation from mean scores for indicator $\mathrm{j}$. The length of this vector is given by the square root of the inner product of the vector. That is:

$$
\left|X_{i j}-\bar{X}_{j}\right|=\left[\left(X_{i j}-\bar{X}_{j}\right),\left(X_{i j}-\bar{X}_{j}\right)\right]^{1 / 2}=\sum_{i=1}^{n}\left(X_{i j}-\bar{X}_{j}\right)^{2}
$$

From the definition of variance we have:

$$
\sigma^{2}=\frac{\sum_{i=1}^{n}\left(X_{i j}-\bar{X}_{j}\right)^{2}}{n}
$$

Or:

$\sum_{i=1}^{n}\left(X_{i j}-\bar{X}_{j}\right)^{2}=n \sigma^{2}$

Bearing in mind that the variance of a standardised indicator is equal to 1 , from the first and third equations we will have:

$\left|X_{i j}-\bar{X}_{j}\right|=n^{1 / 2}$

That is, the length of a standardised indicator is equal to the square root of the number of regions which remains the same for all indicators. Hence the length of the standardised indicator vectors are equal. 
${ }^{12}$ This is based on the expectation that in a normal distribution approximately $95 \%$ of cases fall between the mean plus 2 standard deviation and the mean minus 2 standard deviation.

13 One might wish to divide these targets to short run, medium run and long run targets according to their ranges (eg, below, around or above the means, respectively). 